Abstracta Iranica Abstracta Iranica

Revue bibliographique pour le domaine irano-aryen

Volume 25 | 2004

Comptes rendus des publications de 2002

Celebrating a Sufi Master - A Collection of Works on the Occasion of the First International Symposium on Shah Nematollah Vali. Sponsored by San Jose State University, Simorgh Sufi Society, Greenlawn, NY, 2002, 183 p.

Pierre Lory

\title{
CpenEdition
}

Édition électronique

URL : http://journals.openedition.org/abstractairanica/4905

DOI : 10.4000/abstractairanica.4905

ISSN : 1961-960X

Éditeur :

CNRS (UMR 7528 Mondes iraniens et indiens), Éditions de l'IFRI

Édition imprimée

Date de publication : 15 mai 2004

ISSN : 0240-8910

Référence électronique

Pierre Lory, "Celebrating a Sufi Master - A Collection of Works on the Occasion of the First International Symposium on Shah Nematollah Vali. Sponsored by San Jose State University, Simorgh Sufi Society, Greenlawn, NY, 2002, 183 p. », Abstracta Iranica [En ligne], Volume 25 | 2004, document 254, mis en ligne le 15 mars 2006, consulté le 25 septembre 2020. URL : http://journals.openedition.org/ abstractairanica/4905; DOI : https://doi.org/10.4000/abstractairanica.4905

Ce document a été généré automatiquement le 25 septembre 2020.

Tous droits réservés 


\section{Celebrating a Sufi Master - A Collection of Works on the Occasion of the First International Symposium on Shah Nematollah Vali. Sponsored by San Jose State University, Simorgh Sufi Society, Greenlawn, NY, 2002, 183 p.}

Pierre Lory

1 Ces actes d'un colloque consacré à Šāh Ni'mat-Allāh Valī comprennent 14 interventions d'une longueur et d'un degré d'érudition variables. On en retiendra notamment le bilan sur le soufisme contemporain dressé par C.W. Ernst («Cultural Transformations of Contemporary Sufism»), l'étude de J. Esots "Shah Nematollah Vali Kermani as a Mystical Poet », ou "A Comparative Study of Doctrinal Views of Shah Nematollah Vali and Jami» par B. Hejazi et A.Gh. Mogaddam; ou encore les remarques de S. M. Azmayesh sur les rythmes sonores dans les rituels soufis.

\section{INDEX}

Thèmes : 8 . Soufisme 
AUTEURS

PIERRE LORY

EPHE - Paris 